\title{
Evaluation of Corporate Social Responsibility Based on Extension Theory
}

\author{
Guihua Wang ${ }^{1,2}$, Lingyun Cheng ${ }^{2}$ \\ ${ }^{1}$ College of Economics and Management, \\ Nanjing University of Aeronautics and Astronautics, \\ Nanjing, China \\ ${ }^{2}$ College of Trade and Logistics, \\ Jiangsu Institute of Commerce, \\ Nanjing, China
}

\begin{abstract}
Evaluation of corporate social responsibility is an important prerequisite for partner selection, harmonious relationship building and sustainable development. In order to make objective evaluation of corporate social responsibility, extension theory is used for the first time to evaluate corporate social responsibility in this paper. Based on the previous study, we build a matter-element model for corporate social responsibility, and make a quantitative analysis in all dimensions of responsibility level by calculating the comprehensive dependent degree combined with case studies. The result shows that extension evaluation of corporate social responsibility can reveal different levels of corporate social responsibility as well as the tendency of responsibility transform, which is conducive to dynamically adjustment of the management strategies and continuous improvement of the enterprises' competitiveness.
\end{abstract}

Keywords-corporate social responsibility; extension evaluation; matter-element model; dependent function

\section{INTRODUCTION}

Corporate social responsibility (CSR) is an important way for enterprises to achieve sustainable development. However, the lack of CSR has exacerbated the deterioration of the enterprises' relationship, harmed the interests of enterprises and customers, and even the whole society, ecological environment construction and sustainable development. For the stakeholders, enterprises with high level of CSR are trustworthy and reliable partners.

At present, most of the researches on CSR evaluation focus on two aspects. one is the study on the evaluation index system, such as constructing evaluation system from four aspects of economic, that is legal, ethical and philanthropic responsibilities [1], building the evaluation framework from responsibility performance, such as economic benefits, ecological benefits, social benefits and other aspects [2], and designing evaluation index from the perspective of stakeholders [3]. The other is evaluation method application, such as the analytic hierarchy process [4], the fuzzy evaluation method, and the factors and data envelopment analysis [5]. Above all, the researches on CSR evaluation mainly focus on the static and dynamic characteristics of qualitative research, which do not conform to match the dynamic change characteristics of
CSR. It is urgent to make a dynamic and quantitative research on CSR.

The extension evaluation method integrates qualitative analysis and quantitative analysis with the use of correlation function in the extension theory to evaluate things $[6,7,8]$, making the evaluation more scientific, objective and fair. In this paper, by combining with the extension matter-element model and the correlation function theory, we build the matter-element model with key indicators evaluation for CSR, calculate the comprehensive correlative degree, and find out the evaluation results of the quantitative value. The evaluation of CSR level is an effective decision-making basis for the enterprise managers.

\section{MATTER-ELEMENT MODEL FOR CSR}

Defining the name of enterprise by $\mathrm{N}$, one of the characteristics of CSR by $c$ and the value of $c$ by $v$, a matter-element in extension theory can be described as follows:

$$
\mathrm{R}=(\mathrm{N}, \mathrm{c}, \mathrm{v})
$$

where, $\mathrm{N}, \mathrm{c}$, and $\mathrm{v}$ are three fundamental elements of CSR matter-element. For example, $\mathrm{R}=$ (enterprise, CSR, high) can be used to state that CSR lever of the enterprise is high. If the value of the characteristic has a classical domain or a range [8], we define the matter-element for the classical domain as follows:

$$
\mathrm{R}=(\mathrm{N}, \mathrm{c}, \mathrm{v})=(\mathrm{N}, \mathrm{c},<\mathrm{a}, \mathrm{b}>)
$$

where, $\mathrm{a}, \mathrm{b}$ are the lower bound and upper bound of $\mathrm{a}$ classical domain.

According to the matter-element theory [6], we must define the social responsibility factors of the enterprises before evaluating the level of CSR. With the experts' experience and related statistic data, the numerical value fields of the responsibility factors are confirmed and the matter-element model of CSR is set up as follows:

$$
R_{i}=(N, C, X)=\left[\begin{array}{ccc}
N, & C_{1} & x_{1} \\
& C_{2} & x_{2} \\
& \vdots & \vdots \\
& C_{n} & x_{n}
\end{array}\right]=\left[\begin{array}{ccc}
N, & C_{1} & <a_{1}, b_{1}> \\
& C_{2} & <a_{2}, b_{2}> \\
\vdots & \vdots \\
& C_{n} & <a_{n}, b_{n}>
\end{array}\right]
$$


where, $N$ stands for the level of CSR, $C_{i}(i=1,2, \ldots n)$ stands for responsibility factors of CSR respectively, which is hereinafter named Eigen factor. $x_{i}(i=1,2, \ldots n)$ are the numerical value fields of responsibility factors $C_{i}$ about CSR level of $N$, namely, classical field $<a_{i}, b_{i}>$.

\section{KEY RESPONSIBILITY FACTORS AND VALUE RANGE}

We integrate the stakeholders and the responsibility content, combined with the existing literature research and 2012 China's evaluation system of CSR. Considering the hierarchy, difficulty and authenticity to get external data of CSR, we refine the key indexes from all levels of CSR, which is representative, real and easy access. The key factors of CSR are divided into: economic responsibility and legal responsibility $\left(C_{1}\right)$, moral responsibility $\left(C_{2}\right)$ and charitable responsibility $\left(C_{3}\right)$. Each key responsibility is subdivided into several key factors of responsibility as follows.

\section{A. Economic and legal responsibility $C_{1}$}

The enterprises' economic and legal responsibility refers to production and operation by law, meeting the consumer demand, and ensuring the rights and interests of shareholders and consumers. According to stakeholder theory, the economic and legal responsibility is divided into responsibility to shareholders $\left(C_{11}\right)$, responsibility to employees $\left(C_{12}\right)$ and responsibility to consumers $\left(C_{13}\right)$.

(i) Responsibility to shareholders $C_{11}$

The enterprises' responsibility to shareholders includes ensuring the shareholders' right by the law, holding the shareholders' respect, sharing the information of management and investment, such as financial statements, CSR report to the shareholders. Considering the responsibility to shareholders mainly includes the economic responsibility, so we use the rate of return on equity to reflect the level of responsibility to shareholders as follows:

$$
C_{11}=\frac{P}{E} \times 100 \%
$$

where $P$ is the corporate profit after tax; $E$ is the net assets of the enterprise.

(ii) Responsibility to employees $C_{12}$

The enterprises' responsibility to employees includes respecting the employees' rights to ensure the welfare of employees, ensuring a safe work environment, regular training and so on. The premise responsibility is to retain employees, but in most cases, employees will leave because wages are not high or treatment is not good enough. So here we measure the responsibility to the employee with the ratio of average wage level of employee benefits and the same industry standards as follows:

$$
C_{12}=\frac{\frac{1}{\mathrm{n}} \sum_{\mathrm{i}=1}^{\mathrm{n}} \mathrm{c}_{\mathrm{i}}}{C}
$$

where $c_{i}$ is the enterprise's salary welfare spending; $n$ is the number of employees; $C$ is the industry average salary for employees.

(iii) Responsibility to consumers $C_{13}$

The enterprises' responsibility to consumers includes providing good products or services to consumers, ensuring safety product, good service and even after sale. Customer satisfaction is the fundamental performance of responsible enterprise, customer complaint rate can intuitively reflect the customer satisfaction. So we use the consumer complaint rate to reflect consumer level of responsibility as follows:

$$
C_{13}=\frac{N_{c}}{N_{b}} \times 100 \%
$$

where $N_{c}$ is the total number of the dissatisfied consumers; $N_{b}$ is the total number of transactions.

\section{B. Moral responsibility $C_{2}$}

Moral responsibility is that the enterprises should conscientiously carry out equal transaction, honesty and trustworthiness, ethics and responsibility of saving resources, protecting environment during production and business activities. According to stakeholder theory, the moral responsibility can be divided into responsibility to partners $\left(C_{21}\right)$ and responsibility to environment $\left(C_{22}\right)$.

(i) Responsibility to partners $C_{21}$

The enterprises' responsibility to partners is that the enterprises should maintain equality, honesty, profit space, full cooperation and information transparency during cooperation. Attitude and response speed of partners can reflect the enterprise's willingness to cooperate and the extent of cooperation manifested intuitively. So here we use the speed of response to measure the enterprise's responsibility for the partners as follows:

$$
C_{21}=\frac{q_{i}}{Q}
$$

where $Q$ is the average number of instructions for all the same industry enterprises in the $T$ period; $q_{i}$ is the average number of instructions of the enterprise in the $T$ period.

(ii) Responsibility to environment $C_{22}$

The enterprises' responsibility to environment includes environment protection, pollution avoiding, environment governance and so on. Considering the externalities benefits of enterprise's production and activities, here we use the environmental input percentage to reflect the environment responsibility as follows:

$$
C_{22}=\frac{\frac{1}{n} \sum_{i=1}^{n} E_{i}}{\frac{1}{n} \sum_{i=1}^{n} \mathrm{~W}_{i}} \times 100 \%
$$

where $W_{i}$ is enterprises' pre-tax profit in $i$ year, $E_{i}$ is the total environmental investment without production. 


\section{Charitable responsibility $C_{3}$}

Charitable responsibility includes charitable donations, public welfare undertakings, community serve, public facilities construction, and so on.

Considering the current enterprises' excessive pursuit of publicity effect and the neglect of the basic responsibility, we use two indicators to reflect the level of charitable responsibility. One is the responsibility which the enterprise repays the society donation $C_{31}$; the other is the released cycle of CSR report $C_{32}$. If the enterprise can issue CSR report regularly, it means the enterprise takes CSR as a strategy, which can reflect the enterprise's real level of social responsibility and vice versa.

(i) Donation responsibility $C_{31}$

In order to have a continuing responsibility to the society return, we use the annual investment percentage to reflect the level of public responsibility as follows:

$$
C_{31}=\frac{\frac{1}{n} \sum_{i=1}^{n} S_{i}}{\frac{1}{n} \sum_{i=1}^{n} W_{i}} \times 100 \%
$$

where $W_{i}$ is enterprise's pre-tax profit in $i$ year, $S_{i}$ is the total social return.

(ii) Report responsibility $C_{32}$

If the enterprises really have the sense of responsibility, they will reflect the social responsibility management concept in their strategic planning and dayto-day operations, and fulfill the social responsibility of the enterprise layer by layer. CSR report is a good communication way with stakeholders as the provident and embodiment of behavior performance level of CSR. Assuming the enterprise has published $\mathrm{x}$ report on CSR in $\mathrm{n}$ years, so the responsibility report ratio can be described as follows:

$$
C_{32}=\frac{\mathrm{x}}{\mathrm{n}} \times 100 \%
$$

where $x$ is the times publishing annual responsibility report; $n$ is the total number of years.

\section{EXTENSION EVALUATION OF CSR}

\section{A. Dependent function of CSR factors}

After establishing the matter-element model for CSR, it is necessary to compute the dependent degree between the matter-element to be evaluated and the matter-element in the classical field.

(i) Construct simple dependent function of the factors $C_{12}, C_{21}, C_{32}$ :

$$
k_{i j}(x)=\frac{x-a_{i j}}{a_{i j}}
$$

where if $i=1$ then $j=2$;if $i=2$ then $j=1$; if $i=3$ then $j=2$. (ii) Construct general elementary dependent function of the factors $C_{11}, C_{22}, C_{31}$ :

$$
k_{i j}(x)=\frac{\rho\left(x, X_{0}\right)}{D\left(x, X_{0}, X\right)}
$$

where

$$
\begin{aligned}
& \rho\left(x, X_{0}\right)=\left|x-\frac{a_{i j}+b_{i j}}{2}\right|-\frac{b_{i j}-a_{i j}}{2} \\
& \rho(x, X)=\left|x-\frac{c_{i j}+d_{i j}}{2}\right|-\frac{d_{i j}-c_{i j}}{2}
\end{aligned}
$$

$$
D\left(x, X_{0}, X\right)=\left\{\begin{array}{cc}
a_{i j}-b_{i j} & \rho(x, X)=\rho\left(x, X_{0}\right) \\
\rho(x, X)-\rho\left(x, X_{0}\right)+a_{i j}-b_{i j} & \rho(x, X) \neq \rho\left(x, X_{0}\right) \text { and } d x \in X_{0} \\
\rho(x, X)-\rho\left(x, X_{0}\right) & \rho(x, X) \neq \rho\left(x, X_{0}\right) \text { and } x \notin X_{0}
\end{array}\right.
$$

$$
\begin{aligned}
& X_{0}=<a_{i j}, b_{i j}>\text { and } X=<c_{i j}, d_{i j}> \\
& i=1 \quad j=1 \quad i=2 \quad j=2 \quad i=3 \quad \text { Where, if } \\
& \text { then } \quad \text { if } \quad j=1
\end{aligned}
$$

(iii) Construct simple dependent function of the factor $C_{13}:$

$$
k_{i j}(x)=\frac{a_{i j}-x}{a_{i j}}
$$

\section{B. Comprehensive dependent degree of CSR}

After constructing the above dependent functions of the responsibility factors, we need select the weight values of the factors. The weight methods include AHP, Delphi and so on $[9,10]$. The paper supposes that the weight value of $F_{i j}$ is $W_{i j}$,

TABLE I. CSR OF ENTERPRISE A.

\begin{tabular}{|c|c|c|c|c|c|c|}
\hline $\begin{array}{c}\text { Responsibility } \\
\text { Item }\end{array}$ & $\begin{array}{c}\text { Responsibility } \\
\text { Categories }\end{array}$ & $\begin{array}{c}\text { Responsibility } \\
\text { Elements }\end{array}$ & $\begin{array}{c}\text { Classical } \\
\text { Field }\end{array}$ & $\begin{array}{c}\text { Segment } \\
\text { Field }\end{array}$ & & $w_{i j}$ \\
\hline \multirow{4}{*}{$\mathrm{C}_{1}$} & $\mathrm{C}_{11}$ & {$[0.1,0.4]$} & {$[0,1]$} & 0.2 & 0.2 \\
\cline { 3 - 8 } & & $\mathrm{C}_{12}$ & {$[0.5,+\infty]$} & {$[0,+\infty]$} & 0.4 & 0.18 \\
\cline { 3 - 8 } & $\mathrm{C}_{13}$ & {$[0,0.2]$} & {$[0,1]$} & 0.3 & 0.22 \\
\cline { 3 - 8 } & \multirow{3}{*}{$\mathrm{C}_{2}$} & $\mathrm{C}_{21}$ & {$[1,+\infty]$} & {$[0,+\infty]$} & 0.9 & 0.16 \\
\cline { 3 - 8 } & & $\mathrm{C}_{22}$ & {$[0.01,0.2]$} & {$[0,1]$} & 0.05 & 0.14 \\
\cline { 3 - 8 } & \multirow{2}{*}{$\mathrm{C}_{3}$} & $\mathrm{C}_{31}$ & {$[0.001,0.06]$} & {$[0,1]$} & 0.01 & 0.02 \\
\cline { 3 - 8 } & & $\mathrm{C}_{32}$ & {$[0.5,1]$} & {$[0,1]$} & 0.4 & 0.08 \\
\hline
\end{tabular}


TABLE II. THE COMPREHENSIVE EVALUATION OF CSR.

\begin{tabular}{|c|c|c|c|c|c|c|c|c|}
\hline $\begin{array}{c}\text { Responsibility } \\
\text { Categories }\end{array}$ & $\begin{array}{c}\text { Responsibility } \\
\text { Elements }\end{array}$ & $\begin{array}{c}\text { Classical } \\
\text { Field }\end{array}$ & $\begin{array}{c}\text { Segment } \\
\text { Field }\end{array}$ & $x_{i j}$ & $k_{i j}\left(x_{i j}\right)$ & $w_{i j}$ & $w_{i j} k_{i j}\left(x_{i j}\right)$ & $K(x)$ \\
\hline$C_{1}$ & $\mathrm{C}_{11}$ & {$[0.1,0.4]$} & {$[0,1]$} & 0.2 & 0.25 & 0.2 & 0.05 & \\
\hline & $\mathrm{C}_{12}$ & {$[0.5,+\infty]$} & {$[0,+\infty]$} & 0.4 & -0.2 & 0.18 & -0.036 & \\
\hline & $\mathrm{C}_{13}$ & {$[0,0.2]$} & {$[0,1]$} & 0.1 & 0.5 & 0.22 & 0.11 & \multirow{2}{*}{0.079} \\
\hline $\mathrm{C}_{2}$ & $\mathrm{C}_{21}$ & {$[1,+\infty]$} & {$[0,+\infty]$} & 0.9 & -0.1 & 0.16 & -0.016 \\
\hline & $\mathrm{C}_{22}$ & {$[0.01,0.2]$} & {$[0,1]$} & 0.05 & 0.2 & 0.14 & 0.028 & \\
\hline $\mathrm{C}_{3}$ & $\mathrm{C}_{31}$ & $\begin{array}{c}{[0.001,} \\
0.06]\end{array}$ & {$[0,1]$} & 0.01 & 0.15 & 0.02 & 0.003 & \\
\hline & $\mathrm{C}_{32}$ & {$[0.8,1]$} & {$[0,1]$} & 0.2 & -0.75 & 0.08 & -0.06 & \\
\hline
\end{tabular}

where if $i=1$, then $j=1,2,3$; if $i=2,3$, then $j=1,2 ; 0<W_{i j}<1$, and $\sum_{i} \sum_{j} W_{i j}=1$.

The comprehensive dependent degree of CSR is as follows:

$$
K(x)=\sum_{i} \sum_{j} w_{i j} k_{i j}(x)
$$

The comprehensive dependent degree $K(x)$ can not only reflect the overall responsibility level but also reveal the tendency of the responsibility transformation. When $K(x)>0$, the enterprise has fulfilled certain responsibilities. When $K(x)<0$, the enterprise has fulfilled little or no responsibility, and it is necessary to focus on fulfilling responsibility as soon as possible.

\section{EVALUATION EXAMPLE AND ANALYSIS}

In order to illustrate the feasibility and effectiveness of the model, we construct an example according to examples in literature $[6,7,8]$. Assuming the values of CSR factors for enterprise $A$ and the weight values of the responsibility factors are known as Table I.

First, by using the formulas (11), (12), and (16), we get the dependent degree $k_{i j}\left(x_{i j}\right)$ of the factors $C_{i j}$. Second, according to formulas (17), we obtain the dependent degree $K_{i}(x)$ of the categories $C_{i}$. Finally, we can get the comprehensive dependent degree $K(x)=0.079$ by formulas (17) as Table II.

From Table 2, we can get the dependent degrees of $C_{1}$, $C_{2}, C_{3}$ as $0.124,0.012$, and -0.05742 , so $C_{1}>C_{2}>C_{3}$.

The dependent degrees of $C_{12}, C_{21}, C_{32}$ are negative, which means the enterprise has not fulfilled the responsibility in these aspects. In order to improve his social responsibility fulfillment situation, the manager should take some actions to solve the problems. The dependent degrees of $C_{11}, C_{13}, C_{22}$ and $C_{31}$ are more than 0 , which shows that in these respects, the enterprise has fulfilled the responsibility, and its follow-up work is to try to maintain the status, or continue to improve on the existing basis. However, in order to improve the overall level of CSR, the whole work should focus on the aspects of $C_{12}, C_{21}, C_{32}$.

\section{CONCLUSIONS}

Quantitative analysis of CSR has been a very difficult task. On the basis of previous research, this paper has used a new research method - extension analysis, established the matter-element model of CSR, and done a quantitative analysis of the model in all dimensions of responsibility combined with case studies. This extension evaluation can reveal different levels of CSR and the tendency of responsibility transform, it is very helpful for managers to make scientific decision.

\section{ACKNOWLEDGMENTS}

The research work was sponsored by Qing Lan Project of Jiangsu Province and College Philosophical Society Science Foundation of Jiangsu Province under Grant No. 2013SJD630011.

\section{REFERENCES}

[1] Y.X. Cai, Research on the model and the standards of Corporate Social Responsibility Evaluation. Ecological Economy, (12), pp. 126-129, 2011.

[2] Y.L. Chen, H. Zou, Evaluation system of enterprise performance based on environmental value chain.Economic Reforms, (2), pp. $118-122,2012$.

[3] Z.R. Huang, Research on evaluation system and mechanism of CSR, Journal of Jilin College of Industry and Commerce, (1), pp. 73-76, 2013.

[4] W. Cai, The extension set and incompatibility problem. Journal of Scientific Exploration, (1), pp. 81-93, 1983.

[5] Y.P. Huang, H.J. Chen, The extension-based fuzzy modelling method and its applications. In: Proc. IEEE Canada Conference on Electrical and Computer Engineering, pp. 977-982, 1999.

[6] W. Cai, Matter-element model and its application. Scientific and Technical Documents Publishing House, Beijing, 1994.

[7] Y. Li, N. Li, Q.X. Li, The extension analysis of software project. Computers and Applied Chemistry, 25(1), pp. 47-50, 2008.

[8] Guihua Wang, Application of extension theory in evaluation of supply chain flexibility, IEEE GSIS2009, (2), pp. 1287-1291, 2009.

[9] Z.X. Wang, Q.X. Li, An approach to integrate the final weights based on the subjective and objective weights. Communication on Applied Mathematics and Computational Journal, 20(1), pp. 87-91, 2006

[10] Q.X. Li, S.F. Liu, A method of construct the general location value and general elementary dependent function. System Engineering Journal, 24(6), pp. 116-118, 2006. 